\title{
GBEP
}

\section{Condições do trabalho docente: uma análise da carreira na rede municipal de ensino de São Paulo}

Lisete Regina Gomes Arelaro

Márcia Aparecida Jacomini

Nilson Alves de Souza

Kátia Aparecida Santos

\section{Resumo}

A partir dos anos de 1990, Estados e municípios passaram a elaborar ou adequar os planos de carreira, cargos e salários dos profissionais do magistério em face das novas legislações: Constituição Federal de 1988, Emenda Constitucional no 14 de 1996, Lei de Diretrizes e Bases da Educação Nacional de 1996 e, mais recentemente, Resolução do CNE/CEB no 2/2009, Parecer CNE/CEB no 9/2009 e Lei no 11.738/2008 (Lei do Piso). Considerando essa nova legislação, neste texto são analisadas as formas de ingresso, a composição da jornada de trabalho, a progressão na carreira e a composição da remuneração, com base na Lei $n^{\circ} 14.660 / 2007$, que trata do plano de carreira dos profissionais do ensino da rede municipal de São Paulo. Verificou-se que em torno de 90\% dos professores são efetivos; que há várias jornadas de trabalho, das quais numa delas 1/3 das horas é destinado a atividades extraclasse e o professor pode trabalhar até 70 horas semanais. A progressão funcional está baseada em títulos e tempo de serviço, embora a avaliação de desempenho esteja prevista na Lei. Apesar de o piso salarial ser superior ao piso nacional, por ser a cidade mais rica e com um dos maiores custos de vida do País, não se trata de uma remuneração que se destaca como exemplo de valorização do magistério.

Palavras-chave: valorização do magistério; plano de carreira; jornada de trabalho docente; remuneração docente. 


\section{Abstract \\ Teachers' working conditions: an analysis of the career in the public educational system of São Paulo}

Since the 1990's, Brazilian states and municipalities started to formulate or adjust teachers' career plans and salaries according to a new set of laws: the Federal Constitution of 1988, the Constitutional Amendment no. 14 of 1996, the Lei de Diretrizes e Bases da Educação (LDB - Law of Directives and Bases for Education, 1996) and, more recently, the Resolution no. 2/2009 of the Conselho Nacional de Educação (CNE - National Education Council) and the Law no. 11.738/2008. Considering the new legislation, this paper analyzes the different ways of teachers' admission, the composition of their working journey, their career progression and the constitution of their remuneration, based on the municipal Law no. 14.660/2007, which approaches the career plan of the teaching professionals of the public educational system of São Paulo's municipality. It was found that around 90\% of teachers are stable civil servants; also, that there are many different types of working journeys. One particular type of journey includes one third of the working hours destined to extracurricular activities; also, teachers can work up to 70 hours per week. Despite the inclusion of the performance evaluation in the career plan, career progression relies on academic titles and on the length of service. Although the teachers' minimum wage in São Paulo is higher than the national minimum wage, it is important to highlight that São Paulo is the richest city in the country, with the highest cost of living; therefore, it is not possible to assert that this salary stands out as an example of enhancement for the teaching profession.

Keywords: valuation of teaching; career plan; teacher's working journey; teacher's salary.

\section{Introdução}

A partir da década de 1990, com base na Constituição Federal de 1988 (CF/88), na Lei de Diretrizes e Bases da Educação Nacional no 9.394/1996 (LDB/96), na Emenda Constitucional no 14/1996 (EC 14/96), na Lei no 9.424/1996, que regulamentou o Fundo de Manutenção e Desenvolvimento do Ensino Fundamental e de Valorização do Magistério (Fundef), e, mais recentemente, na Resolução da Câmara da Educação Básica do Conselho Nacional de Educação (CNE/CEB) no 2 de 2009, no Parecer CNE/CEB no 9/2009 e na Lei no 11.738/2008 (Lei do Piso), que instituiu o piso salarial profissional nacional, Estados e municípios passaram a elaborar planos de cargos, carreira e salários de forma mais sistemática para os profissionais do magistério ou a adequar os planos já 
${ }^{1}$ Neste texto a palavra progressão será usada como termo genérico que indica a movimentação ou a mobilidade ascendente na carreira.

${ }^{2}$ Quadro será entendido como "o conjunto de carreiras, cargos isolados (incluem os cargos em comissão) e funções gratificadas de um mesmo serviço, órgão ou poder". (Dutra Júnior et al., 2000, p. 204) existentes à legislação e às novas concepções de carreira docente que se conformaram no marco da reforma do Estado (EC nº 19/1998).

Se esse movimento, por um lado, vai ao encontro da reivindicação histórica dos educadores por planos de carreira e salários, por outro, introduz a avaliação de desempenho como condição de progressão funcional, ${ }^{1}$ vinculada aos resultados dos alunos nos testes de larga escala nacional, estadual ou municipal, medida que tem sido criticada por sindicato e por pesquisadores da área educacional.

Diferentemente da maioria dos municípios brasileiros, que só recentemente construiu seus planos de carreira (Gatti; Barreto, 2009), na rede municipal de ensino de São Paulo, há legislação que regulamenta a vida profissional do professor desde 1967, quando foi instituída a carreira do professor primário. No entanto, foi somente em 1992 que os professores obtiveram um estatuto do magistério. Considerado uma conquista da categoria docente, o Estatuto do Magistério Público Municipal de São Paulo (Lei no 11.229/1992), aprovado na gestão da prefeita Luiza Erundina de Sousa (1989/92), sofreu duas importantes modificações, em atendimento às legislações posteriores e às concepções dos governos municipais subsequentes. A primeira foi realizada em 1993, por meio da Lei no 11.434, no governo Paulo Maluf (1993/96), e a segunda, em 2007, por meio da Lei $n^{\circ}$ 14.660, na administração José Serra/Gilberto Kassab (2005/08).

A Lei $\mathrm{n}^{\circ} 11.434 / 1993$, diferentemente do estatuto de 1992, dispunha sobre a organização dos quadros ${ }^{2}$ dos profissionais da educação, criava novas escalas de vencimentos e instituía planos de carreiras para os quadros do magistério e o de apoio à educação. Essa lei, ao instituir o quadro dos profissionais de educação, incluiu todos os profissionais da escola e de órgãos centrais e intermediários da Secretaria Municipal de Educação (SME). A Lei n 14.660/2007 modifica as duas anteriores, reorganizando o quadro dos profissionais de educação e as respectivas carreiras criadas pela Lei de 1993, e consolida o Estatuto do Magistério Público do Município de São Paulo.

Assim, neste texto será analisada somente a carreira docente, tendo como referência a lei de 2007. De acordo com o documento do Fundescola/ MEC, plano de carreira refere-se a um conjunto de normas que define a condição de progressão na carreira:

O plano de carreira é instrumento de administração de recursos humanos voltado essencialmente para a profissionalização. Nessa condição, considera de forma especial algumas variáveis essenciais à sua finalidade, quais sejam, o desempenho do servidor no exercício de suas atribuições, os programas de desenvolvimento de recursos humanos, a estrutura de classes e o sistema de remuneração. (Dutra Júnior et al., 2000, p. 204)

A rede municipal de São Paulo está entre as maiores redes de ensino do País, com cerca de um milhão de alunos e mais de cinquenta mil professores em 2011. Há quatro sindicatos que atuam na defesa dos trabalhadores em educação: Sindicato dos Profissionais em Educação 
no Ensino Municipal de São Paulo (Sinpeem), Sindicato dos Professores e Funcionários Municipais de São Paulo (Aprofem), Sindicato dos Trabalhadores nas Unidades de Educação Infantil da Rede Municipal de São Paulo (Sedin), Sindicato dos Especialistas de Educação do Ensino Público Municipal de São Paulo (Sinesp).

Com o objetivo de compreender o plano de carreira do magistério da cidade de São Paulo, no marco da legislação recente e das novas concepções de carreira, serão analisadas a forma de ingresso, a composição da jornada de trabalho, a progressão na carreira e a composição da remuneração. Busca-se verificar, também, em que medida essa nova concepção de carreira docente, que vincula progressão funcional ou benefícios salariais a resultado dos alunos nos testes de alto impacto, tem sido incorporada ao plano da rede municipal de São Paulo e problematizar a relação entre qualidade da educação e esse modelo de avaliação dos professores.

\section{Ingresso na carreira docente}

De acordo com a Lei $n^{\circ} 14.660 / 2007$, o quadro dos profissionais da educação, dividido em quadro do magistério (docentes e gestores educacionais) e quadro de apoio à educação (demais funcionários da escola), é composto por cargos de provimento efetivo e em comissão. ${ }^{3}$ A efetivação no cargo dar-se-á após os três anos de estágio probatório, conforme disposto na EC nº 19/1998. O ingresso na carreira para docentes, que envolve os cargos de professor de educação infantil, professor de educação infantil e ensino fundamental I e professor de ensino fundamental II e médio, ocorre mediante concurso público de provas e títulos. O ingresso na carreira do magistério por meio de concurso público está previsto na CF/88 e na LDB/96 e faz parte das reivindicações dos sindicatos de professores. A defesa do concurso público contrapõe-se às práticas de indicação (clientelismo/apadrinhamento) por políticos que buscam compor sua base de apoio, utilizando-se do emprego no serviço público.

Na rede municipal de São Paulo, a maioria dos professores é concursada. De acordo com dados obtidos na Secretaria Municipal de Educação, em 2010, dos 56.872 profissionais do magistério da rede municipal de ensino de São Paulo, 50.676 (89,1\%) eram efetivos. Desde 1992, quando o Estatuto do Magistério estabeleceu que os concursos públicos deveriam ser realizados a cada dois anos ou quando o percentual de cargos vagos atingisse $5 \%$ do total de cargos da respectiva área (São Paulo, 1992, § $1^{\circ}$, art. $7^{\circ}$ ), a administração pública municipal tem realizado concursos regularmente.

Além dos professores concursados, há aqueles que adquiriram estabilidade no serviço público, de acordo com o art. 19 do Ato das Disposições Constitucionais Transitórias da CF/88. A rede conta ainda com professores que são contratados por meio de contrato temporário de
${ }^{3}$ Cargo em comissão só admite provimento em caráter provisório. Os cargos são permanentes, mas a permanência no cargo é sempre precária, pois quem o exerce não adquire o direito de continuar no cargo (Dutra Júnior et al., 2000). 
trabalho pelo prazo máximo de doze meses, podendo ser renovado por igual período (São Paulo, 2007, art. 108).

Todo profissional concursado, atendendo ao disposto na EC $\mathrm{n}^{\circ}$ 19/1998, deve passar por um período de estágio probatório de três anos de efetivo exercício. Após esse período, o servidor deve ser submetido a uma avaliação especial de desempenho para adquirir a estabilidade, de modo que "o servidor que após o cumprimento do estágio probatório não adquirir a estabilidade será exonerado" (art. 33, § $4^{\circ}$ ).

\section{Jornada de trabalho docente}

A definição de uma jornada de trabalho compatível com a especificidade do trabalho docente está diretamente relacionada à valorização do magistério e à qualidade do ensino, uma vez que a dupla ou a tripla jornadas comprometem o desempenho do professor.

Ao discutir a valorização salarial dos professores do ensino público, João Monlevade (2000) alerta para a relação entre desvalorização salarial e aumento da jornada de trabalho no magistério público.

\footnotetext{
Premida pela demanda de novos alunos, ou espremida pelo baixo salário, a professora duplicou e até triplicou sua jornada de trabalho na escola. Se fosse professora particular nos dois turnos, certamente teria dobrado o salário. No caso das professoras de redes públicas, a tendência foi outra: mais turnos e horas de trabalho e o salário proporcionalmente menor. No caso de uma combinação de patrões diferentes - públicos federal, estadual e municipal e privados ou comunitários - , os ganhos e perdas salariais com a multiplicação de turnos podiam ser e realmente foram os mais diversos. O que importa é a tendência à sobrecarga do trabalho direto com a desvalorização salarial e a desqualificação da profissão. (Monlevade, 2000, p. 70)
}

As discussões mais recentes sobre jornada têm reafirmado a necessidade de o professor ter uma única jornada e trabalhar somente numa escola, o que garante melhores condições de trabalho. Respeitando a diversidade e a especificidade das redes de ensino, a Resolução CNE/ CEB no 2/2009 propõe que as secretarias de educação façam esforços no sentido de avançar rumo à jornada integral de 40 horas/semanais, com a vinculação do professor a uma única escola.

De acordo com a LDB/96 e a Lei de Piso, a jornada de trabalho docente deve ser composta por um percentual de horas destinadas às atividades de preparação de aula, correção de atividades, atendimento aos pais, formação continuada, desenvolvimento de trabalho coletivo na escola, entre outras atividades inerentes ao trabalho do professor.

Na rede municipal de ensino da cidade de São Paulo, há dois tipos de jornadas de trabalho para os docentes: as jornadas básicas e as jornadas especiais de trabalho. As jornadas básicas realizam-se de duas formas:

1 - Jornada básica de 30 horas semanais de trabalho (J-30), para o cargo de professor da educação infantil, cumprida exclusiva- 
mente nos Centros de Educação Infantil (CEIs). ${ }^{4}$ Ela é composta por 25 horas em regência de turma e 5 horas/atividades. Destas, três horas são de trabalho coletivo e duas de trabalho individual cumpridas na escola.

2 - Jornada básica do docente (JBD), de 30 horas-aula de trabalho semanal (22 horas e 30 minutos), destinada ao cargo de professor de educação infantil e ensino fundamental I e ao cargo de professor de ensino fundamental II e médio. Nessa jornada, cinco horas-aula são reservadas para atividades extraclasse, sendo três cumpridas obrigatoriamente na escola e duas em local de livre escolha. ${ }^{5}$

Observe-se que para o professor que trabalha no CEI a jornada é definida por hora-relógio (60 minutos) e para as demais jornadas a hora/ aula corresponde a 45 minutos.

As jornadas especiais de trabalho compreendem:

1 - Jornada especial integral de formação (JEIF), composta por 25 horas-aula em regência de classe e 15 horas-aula adicionais (30 horas). Os professores de educação infantil e ensino fundamental I e de ensino fundamental II e médio podem solicitar anualmente o ingresso nessa jornada, porém ela é autorizada se o professor estiver em regência de classe. Do total de quinze horas-aula adicionais, onze devem ser cumpridas obrigatoriamente na escola (oito de trabalho coletivo e três de trabalho individual) e as quatro restantes em local de livre escolha.

2 - Jornada especial de trabalho excedente (TEX) e jornada especial de horas-aula excedentes (JEX). Horas de trabalho excedentes são aquelas que excedem a carga horária regular do professor e que são destinadas à participação em projetos especiais de ação ${ }^{6}$ (PEAs), quando relativas à TEX, ou às horas-aula ministradas pelo professor, quando relativas à JEX.

De acordo com as necessidades da escola, o diretor pode atribuir, mediante anuência do profissional, horas excedentes que compõem essas duas jornadas para os professores de educação infantil e ensino fundamental I e ensino fundamental II e médio. Aos professores de educação infantil somente podem ser atribuídas horas excedentes relativas à TEX.

A concepção da JEIF estava presente no estatuto de 1992, na proposta de uma jornada de tempo integral (JTI) de 30 (trinta) horas, quando, pela primeira vez, a rede municipal de ensino da cidade de São Paulo conquistou uma jornada de trabalho que destinava $1 / 3$ de suas horas às atividades extraclasse, conforme proposta na Lei do Piso.

A concepção de destinar $1 / 3$ da jornada docente para atividades extraclasse foi mantida nas leis subsequentes, embora sua denominação tenha mudado. No entanto, destaca-se que a proporção de horas para atividades extraclasse não é a mesma em todas as jornadas e, no caso dos professores de educação infantil que trabalham nos CEIs, a proporção de
${ }^{4}$ CEI refere-se às antigas creches que foram transferidas da Secretaria Municipal da Cidadania e Bem-Estar Social para a Secretaria de Educação.

${ }^{5}$ A Lei $n^{\circ} 14.660 / 2007$ extingue a Jornada Básica (JB) de 20 horas-aulas. Sendo assim, a JB entra em vacância, restando apenas alguns servidores nessa jornada.

6 Segundo a Portaria $\mathrm{n}^{0}$ 1.566/2008, art. 10, "Os Projetos Especiais de Ação (PEAs) são instrumentos de trabalho elaborados pelas Unidades Educacionais, que expressam as prioridades estabelecidas no Projeto Pedagógico, voltadas essencialmente às necessidades dos educandos, definindo as ações a serem desencadeadas e as responsabilidades na sua execução e avaliação, visando ao aprimoramento das práticas educativas e consequente melhoria da qualidade de ensino [...]." 
horas para atividades extraclasse é bem inferior a 1/3, correspondendo a $1 / 6$ da jornada. Nesse sentido, somente uma das cinco jornadas da rede municipal de São Paulo atende ao disposto na Lei do Piso, que tampouco prioriza a jornada de tempo integral com o máximo de 40 horas semanais, como recomenda a Resolução CNE/CEB nº 2/2009. Essa condição acaba por estimular o acúmulo de cargo, que na rede municipal de São Paulo pode ser de até 70 horas semanais de trabalho.

Não restam dúvidas de que 70 horas semanais de trabalho são incompatíveis com um bom desempenho profissional e representam um absoluto desrespeito ao trabalhador. Tal absurdo somente pode ser compreendido no marco dos baixos salários que há tempos têm sido compensados com o aumento da jornada de trabalho. Por isso, constata-se certa pressão contraditória dos professores e do sindicato pela manutenção do direito ao acúmulo.

\section{Progressão na carreira}

Dois aspectos principais polarizam o debate sobre a progressão na carreira: 1) a dispersão salarial, ou seja, a distância entre a menor e a maior remuneração e 2) os critérios adotados para a progressão na carreira.

A progressão na carreira nos termos da Lei $n^{\circ}$ 14.660/2007 define o padrão de vencimento com base em um conjunto de referências e graus. As referências são posições na escala de padrões de vencimentos organizadas verticalmente. Para os docentes, a primeira referência é identificada com o número 11, seguindo, sucessivamente, até o número 21. Os graus, em número de cinco, são organizados horizontalmente e representados por letras de $\mathrm{A}$ a E.

A diferença entre cada uma das referências e dos graus é de 6,5\%, permitindo, assim, uma dispersão no vencimento de 141,5\%. A Tabela 1 expressa de forma objetiva essa dispersão no vencimento.

Tabela 1 - Dispersão Salarial

\begin{tabular}{|r|r|r|r|r|r|}
\hline Referência/Grau & \multicolumn{1}{|c|}{ A } & \multicolumn{1}{c|}{ B } & \multicolumn{1}{c|}{ C } & \multicolumn{1}{c|}{ D } & \multicolumn{1}{c|}{ E } \\
\hline $\mathbf{1 1}$ & 100 & 106,5 & 113,4 & 120,8 & 128,6 \\
\hline $\mathbf{1 2}$ & 106,5 & 113,4 & 120,8 & 128,6 & 137 \\
\hline $\mathbf{1 3}$ & 113,4 & 120,8 & 128,6 & 137 & 145,9 \\
\hline $\mathbf{1 4}$ & 120,8 & 128,6 & 137 & 145,9 & 155,4 \\
\hline $\mathbf{1 4}$ & 128,6 & 137 & 145,9 & 155,4 & 165,5 \\
\hline $\mathbf{1 4}$ & 137 & 145,9 & 155,4 & 165,5 & 176,3 \\
\hline $\mathbf{1 4}$ & 145,9 & 155,4 & 165,5 & 176,3 & 187,7 \\
\hline $\mathbf{1 4}$ & 155,4 & 165,5 & 176,3 & 187,7 & 199,9 \\
\hline $\mathbf{2 1}$ & 165,5 & 176,3 & 187,7 & 199,9 & 121,9 \\
\hline
\end{tabular}

Fonte: Tabela elaborada pelos autores a partir da Lei $\mathrm{n}^{\circ} 14.660 / 2007$. Obs: Nesta tabela a referência/grau inicial (11A) corresponde a 100. 
Há duas formas de progressão na carreira: 1) por Evolução Funcional, que corresponde à passagem de uma referência a outra, respeitados os critérios de tempo, de títulos ou a combinação de ambos, prevista na Lei $n^{\circ} 14.660 / 2007$ (art. 35) e 2) por Promoção, prevista no art. 67 da Lei no 8.989/1979 (Estatuto dos Funcionários Públicos do Município de São Paulo).

A promoção pode ocorrer por antiguidade e por merecimento. No caso da promoção por antiguidade, respeitar-se-á o interstício de três anos de efetivo exercício no grau. A promoção por merecimento requer dois anos de efetivo exercício no cargo e poderá ocorrer anualmente se o servidor tiver pontuação para tal. Do total dos funcionários de cada grau em cada classe, $16 \%$ podem ser promovidos por antiguidade. A promoção por merecimento é feita por meio de avaliação de desempenho pela chefia imediata e por autoavaliação.

Os professores podem ser enquadrados, de acordo com sua titulação acadêmica, em duas categorias: Categoria 1, dos docentes com habilitação específica em nível de ensino médio (normal ou magistério), somente para os professores de educação infantil e os professores de educação infantil e ensino fundamental I; e Categoria 3, dos docentes com titulação de nível superior (licenciatura plena), para os professores de ensino fundamental II e ensino médio.

A Tabela 2 explicita as posições inicial e final na escala de padrões de vencimentos por titulação dos docentes. ${ }^{7}$

Tabela 2 - Posição Inicial e Final na Escala de Padrões de Vencimentos por Titulação

\begin{tabular}{|l|c|c|c|}
\hline \multicolumn{1}{|c|}{$\begin{array}{c}\text { Titulação } \\
\text { necessária }\end{array}$} & $\begin{array}{c}\text { Categoria 1 } \\
\text { Ensino médio } \\
\text { Modalidade } \\
\text { Normal }\end{array}$ & $\begin{array}{c}\text { Categoria 3 } \\
\text { Licenciatura } \\
\text { Plena }\end{array}$ & $\begin{array}{c}\text { Distância entre } \\
\text { as categorias 1 } \\
\text { e 3 }\end{array}$ \\
\hline $\begin{array}{l}\text { Posição inicial na } \\
\text { Escala de Padrões } \\
\text { de Vencimentos }\end{array}$ & $11 \mathrm{~A}$ & $14 \mathrm{~A}$ & $21 \%$ \\
\hline $\begin{array}{l}\text { Posição final na } \\
\text { Escala de Padrões } \\
\text { de Vencimentos }\end{array}$ & $18 \mathrm{E}$ & $21 \mathrm{E}$ & $21 \%$ \\
\hline
\end{tabular}

Fonte: Tabela elaborada pelos autores com base na Lei $n^{\circ} 14.660 / 2007$.

Embora a dispersão no vencimento, conforme Tabela 1, seja de $141,5 \%$, se considerarmos apenas a dispersão em cada categoria, ela é de aproximadamente $100 \%$, devido às posições inicial e final, conforme apresentado na Tabela 2. O professor pode solicitar enquadramento na Categoria 3 em qualquer momento da carreira, apresentando diploma de licenciatura plena.

A evolução funcional do professor, baseada no tempo de serviço no cargo, ocorre de acordo com a periodicidade apresentada na Tabela 3.
${ }^{7}$ Em 2011, o valor do padrão de vencimento para a jornada básica docente (JBD) -30 horas-aula, que correspondem a 22 horas e 30 minutos, na referência $11^{\text {a }}$ era de $\mathrm{R} \$ 1.172,29$ e na $14^{\mathrm{a}}$, de $\mathrm{R} \$ 1.416,13$. 
Tabela 3 - Interstício para Evolução Funcional

\begin{tabular}{|c|c|c|}
\hline \multirow{2}{*}{ Referência } & Categoria 1 & Categoria 2 \\
\hline 11 & Tempo & Tempo \\
\hline 12 & 0 & \\
\hline 13 & 3 & \\
\hline 14 & 5 & 0 \\
\hline 15 & 12 & 3 \\
\hline 16 & 16 & 8 \\
\hline 17 & 20 & 12 \\
\hline 18 & & 16 \\
\hline 20 & & 20 \\
\hline 21 & & 22 \\
\hline
\end{tabular}

Fonte: Tabela elaborada pelos autores a partir da Lei $n^{\circ}$ 14.660/2007.

Conforme mostra a Tabela 3, o professor pode chegar à última referência, se tiver evolução funcional somente por tempo, após 22 anos de exercício.

A evolução funcional baseada em títulos compreende: cursos de graduação, pós-graduação, especialização, cursos promovidos, reconhecidos ou patrocinados pelo órgão técnico da SME e tempo de exercício no cargo. A esses títulos são atribuídos pontos, de acordo com tabela específica, para a mudança de referência. Essa forma de evolução permite que o professor chegue à última referência num período de tempo inferior aos 22 anos, conforme apresentado na Tabela 3.

A evolução por título respeita o interstício mínimo de um ano na mesma referência, sendo que a primeira evolução funcional só poderá ser solicitada após o cumprimento dos três anos de período probatório.

Em estudo sobre os professores brasileiros, Gatti e Barreto (2009) encontraram três categorias de titulação com salários diferenciados: nível médio (modalidade normal), graduação em nível superior e pósgraduação. No caso do município de São Paulo, a formação em pósgraduação (lato sensu, mestrado ou doutorado) não é considerada para fins de enquadramento. Essa formação é contabilizada como titulação acadêmica (com pontuação previamente estabelecida) para a soma da pontuação necessária à evolução funcional por títulos.

Se por um lado pode-se inferir que o plano de carreira da rede municipal de ensino de São Paulo incentiva a formação em nível superior, por outro não estimula a formação em pós-graduação.

Essa questão pode ser verificada também no fato de a Secretaria Municipal de Educação não ter regulamentado, até 2011, o direito de afastamento para frequentar cursos de pós-graduação, conforme previsto no art. 53, inciso II, da Lei $\mathrm{n}^{\circ}$ 14.660/2007. 
Assim, se um professor da rede municipal de São Paulo, na impossibilidade de afastamento para estudos, afastar-se por meio de licença para interesses pessoais (LIP), para fazer mestrado ou doutorado, por um período de três ou quatro anos, ao término do curso, a pontuação que ele receberá por essa titulação para efeitos de evolução funcional será menor que a pontuação daqueles que permaneceram no exercício do cargo. Isso ocorre porque o tempo de exercício pode ser transformado em título e utilizado para a evolução funcional por títulos.

Importa destacar que foi reivindicação sindical que os cursos de especialização, mestrado e doutorado não fossem considerados condição para enquadramento. Entendeu-se que, como poucos professores teriam oportunidade de fazer esses cursos, a maioria não chegaria ao final da carreira, caso eles fossem condição para enquadramento, tal como o diploma de licenciatura plena.

Assim, as principais atividades realizadas pelos professores para a evolução funcional baseada em títulos são: participação em atividades de formação continuada e aprimoramento profissional e pontuação pelo exercício no magistério. Além dos cursos realizados fora do horário de trabalho, também são computados para evolução por títulos a pontuação recebida por participação em projetos realizados na escola, a exemplo dos projetos especiais de ação (PEAs); por participação como membros de conselho de escola e de associação de pais e mestres; e por produção acadêmica, científica e cultural.

Os professores que exerceram função docente na rede municipal de ensino em período anterior ao da efetivação no cargo podem aproveitar esse tempo a partir da segunda evolução, aplicando tabela específica que combina os critérios para evolução por tempo e título.

\section{Composição da remuneração}

A remuneração dos professores da rede municipal de ensino de São Paulo é composta pelo vencimento ${ }^{8}$ e pelas vantagens pecuniárias estabelecidas em lei. Assim, a remuneração é definida com base na jornada do professor, considerando o conjunto de grau e referência, de acordo com a progressão na carreira.

Na Tabela 4 são apresentados os padrões de vencimento referentes aos cargos na JBD, que correspondem à jornada de ingresso na carreira para professores que atuam na educação infantil (crianças de quatro a cinco anos de idade), no ensino fundamental e no médio.

A cada jornada de trabalho do professor corresponde uma tabela de padrão de vencimento. Contudo, o valor da remuneração guarda relação direta com o número de horas de cada jornada, como ilustra a Tabela 5.

Como se pode observar na Tabela 5 , as jornadas J30 e JEIF correspondem exatamente ao dobro dos vencimentos da JB.
8 Vencimento "é a retribuição pecuniária pelo exercício do cargo público, com valor fixado l[...]" (Dutra Júnior, et al., 2000, p. 215) 
Tabela 4 - Padrão de Vencimento referente ao Cargo de Professor na JBD 2011 (em R\$)

\begin{tabular}{|c|c|c|c|c|c|}
\hline Referência/Grau & A & B & C & D & E \\
\hline 11 & $1.172,29$ & $1.248,55$ & $1.329,67$ & $1.416,13$ & $1.508,17$ \\
\hline 12 & $1.248,55$ & $1.329,67$ & $1.416,13$ & $1.508,17$ & $1.606,20$ \\
\hline 13 & $1.329,67$ & $1.416,13$ & $1.508,17$ & $1.606,20$ & $1.710,61$ \\
\hline 14 & $1.416,13$ & $1.508,17$ & $1.606,20$ & $1.710,10$ & $1.821,80$ \\
\hline 15 & $1.508,17$ & $1.606,20$ & $1.710,61$ & $1.821,80$ & $1.940,22$ \\
\hline 16 & $1.606,20$ & $1.710,61$ & $1.821,80$ & $1.940,22$ & $2.066,33$ \\
\hline 17 & $1.710,61$ & $1.821,80$ & $1.940,22$ & $2.066,33$ & $2.200,64$ \\
\hline 18 & $1.821,80$ & $1.940,22$ & $2.066,33$ & $2.200,64$ & $2.343,68$ \\
\hline 19 & $1.940,22$ & $2.066,33$ & $2.200,64$ & $2.343,68$ & $2.496,02$ \\
\hline 20 & $2.066,33$ & $2.200,64$ & $2.343,68$ & $2.496,02$ & $2.658,27$ \\
\hline 21 & $2.200,64$ & $2.343,68$ & $2.496,02$ & $2.658,27$ & $2.831,05$ \\
\hline
\end{tabular}

Fonte: Tabela elaborada pelos autores com base no Anexo único do Decreto nº 52.399/2011.

Tabela 5 - Tipo de Jornada, Padrão de Vencimento e Proporção entre as Jornadas - 2011 (em R\$)

\begin{tabular}{|c|c|c|c|c|}
\hline Jornada & $\begin{array}{c}\text { Número de } \\
\text { horas/aulas }\end{array}$ & $\begin{array}{c}\text { Início da } \\
\text { tabela } \\
\mathbf{( 1 1 A )}\end{array}$ & $\begin{array}{c}\text { Final da } \\
\text { tabela } \\
\mathbf{( 2 1 E )}\end{array}$ & $\begin{array}{c}\text { Proporção } \\
\text { referente } \\
\text { a menos } \\
\text { jornada (JB) }\end{array}$ \\
\hline JB & 20 & 781,51 & $1.887,30$ & $100 \%$ \\
\hline JBD & 30 & $1.172,29$ & $2.831,05$ & $150 \%$ \\
\hline J30*/JEIF & 40 & $1.563,01$ & $3.774,60$ & $200 \%$ \\
\hline
\end{tabular}

Fonte: Tabela elaborada pelos autores com base na Lei n 14.660/2007 e nas tabelas de vencimento de 2011

*A Jornada (J30) não é constituída por horas aula (45 min. ), mas por hora relógio (60 min.), para efeitos de cálculos os autores a transformaram em horas aula.

Em consonância com a LDB/96 (art. 67), que define a necessidade de previsão de piso salarial nos planos de carreira, a Lei $n^{\circ} 14.660 / 07$ apresenta o piso salarial profissional como forma de valorização do magistério. O art. 100 define que o piso salarial "será fixado anualmente, no mês de maio, em negociação coletiva, que será submetida à aprovação da Câmara Municipal" e "será reajustado de acordo com a legislação que rege os reajustes salariais dos servidores municipais".

Anteriormente à aprovação do plano de carreira, em 2006 foi

${ }_{9}^{9}$ Foram criadas as seguintes gratificações: Gratificação de Regência, Gratificação de Atividade Educativa, Gratificação de Apoio Educacional, Gratificação de Atribuição Educacional, Gratificação Especial para Especialistas, Gratificação de Apoio à Educação, Gratificação por Desenvolvimento Socioeducativo. aprovada a Lei $n^{\circ} 14.244$, que instituiu um conjunto de gratificações ${ }^{9}$ e o abono complementar, que garantia que nenhum professor tivesse vencimentos inferiores ao limite fixado (LF), podendo ser entendido como o estabelecimento de um piso salarial.

Essa lei previa que o abono complementar existiria até a reestruturação da carreira do magistério municipal. Contudo, mesmo após a aprovação do novo plano de carreira, o complemento para se atingir o limite fixado permaneceu. 
Em 2008, foi aprovada a Lei $n^{\circ} 14.709$, que dispunha sobre reajuste nas escalas de padrões de vencimentos e sobre a incorporação das gratificações e do abono complementar, que atingiu 37,5\% em 2010.

Ao final da aplicação dos reajustes concedidos, porém, o limite fixado pela Lei n ${ }^{\circ} 14.244 / 06$ ainda era superior ao padrão de vencimentos para os professores que estavam nas primeiras posições da carreira. Dessa forma, a extinção do abono complementar em 2010, previsto em lei, significaria redução da remuneração para uma parte dos professores.

Em 2010 foi aprovada a Lei $n^{0} 15.215$, que dispunha sobre o reajuste na escala de padrões de vencimentos, alterava a lei do abono complementar e estabelecia um índice de reajuste de 33,79\%, em três parcelas, a partir de 2011. Perpassado o período de incidência das três parcelas de reajustes, o abono complementar seria extinto e incorporado.

Contudo, em 2011, a aprovação da Lei no 15.490 estabeleceu limite fixado superior, restando uma diferença de $13,43 \%$, que será aplicado em 2014.

Tabela 6 - Limite Fixado para cada Jornada de Trabalho - 2011 - (em R\$)

\begin{tabular}{|c|c|c|r|}
\hline Categorias & JB & JBD & \multicolumn{1}{|c|}{ JEIF e J30 } \\
\hline 1 & $1.076,11$ & $1.614,23$ & $2.152,27$ \\
\hline 2 & $1.220,56$ & $1.830,95$ & $2.441,20$ \\
\hline 3 & $1.300,00$ & $1.950,00$ & $2.660,00$ \\
\hline
\end{tabular}

Fonte: Tabela elaborada pelos autores com base na Lei n $15.490 / 2011$.

Além do vencimento fixado para cada jornada de trabalho e das vantagens decorrentes da evolução funcional e da promoção, os professores recebem quinquênios, conforme estabelecido no Estatuto dos Funcionários Públicos do Município de São Paulo. A Lei estabelece que a cada período de cinco anos, contínuos ou não, o funcionário receba adicional por tempo de serviço público municipal, na seguinte proporção: de 5 a 10 anos - 5\%; de 10 a 15 anos -10,25\%; de 15 a 20 anos -15,76\%; de 20 a 25 anos - 21,55\%; de 25 a 30 anos - 27,63\%; de 30 a 35 anos - 34,01\%; mais de 35 anos - 40,71\%. O adicional é calculado sobre o padrão do cargo que o funcionário estiver exercendo e é incorporado à remuneração. Além dos quinquênios, o professor que completar 20 anos de efetivo exercício no serviço público municipal tem direito a receber a sexta parte, que corresponde a 1/6 do seu vencimento.

Acrescentam-se às vantagens pecuniárias permanentes e incorporadas à remuneração para efeitos de aposentadoria as gratificações e os adicionais concedidos por tempo determinado, de acordo com especificações próprias.

Entre as vantagens pecuniárias transitórias está a Gratificação por Local de Trabalho (GLT), para os profissionais da educação que trabalham em unidade escolar que sofre "interferências da conjuntura socioambiental", como dificuldade de lotação de profissionais e baixo Índice de Desenvolvimento Humano (IDH), que corresponderá a 15\% da 
referência 11A, da JBD. A GLT não pode ser acumulada com a Gratificação de Difícil Acesso (GDA), criada pela Lei no 11.035/1991. Contudo, a GLT necessita de regulamentação, o que ainda não ocorreu, estando em vigor somente a GDA, que é calculada sobre o padrão correspondente à classe inicial da respectiva carreira. Os percentuais são de 30\% e de 50\%, a depender da localização da escola na qual o professor trabalha. O adicional noturno, concedido aos professores que lecionam no horário das $19 \mathrm{~h}$ às $23 \mathrm{~h}$, corresponde a 30\% do valor da respectiva hora-aula ou da horatrabalho, sendo contabilizado, também, proporcionalmente, nos descansos semanais, feriados, dias de ponto facultativo, férias, recesso escolar e demais licenças e afastamentos remunerados. O vale-alimentação para todos os professores cuja renda bruta mensal não ultrapassar o equivalente a cinco salários mínimos ${ }^{10}$ em 2011 correspondeu a $\mathrm{R} \$ 234,03$. O auxíliorefeição pago aos professores, exceto àqueles em JB (20 horas-aula), em 2011, correspondia a $\mathrm{R} \$ 12,29$ por dia de trabalho.

Em 2009, por meio da Lei $n^{\circ} 14.938$, foi criado o Prêmio de Desempenho Educacional (PDE), introduzindo-se na rede, pela primeira vez, uma proposta de premiação com base na avaliação de desempenho das escolas. O PDE é pago anualmente aos servidores lotados e em efetivo exercício nas unidades da SME. Essa gratificação não tem natureza de remuneração, não sendo considerada para o cálculo de décimo terceiro, de férias e de aposentadoria. Para ter direito ao PDE, o servidor deve ter iniciado exercício até 31 de maio do ano corrente e ter, no mínimo, seis meses de efetivo exercício nas escolas.

A Lei prevê que os valores estabelecidos anualmente sejam calculados considerando-se o tempo de exercício no cargo ou função e as diretrizes do Sistema de Avaliação Institucional da Educação Municipal. Contudo, esse sistema de avaliação previsto no plano de carreira (Lei no 14.660/07) ainda não foi regulamentado. Diante disso, o governo estabeleceu critérios para o pagamento da gratificação - inexistência de faltas e licença médica - sempre na proporcionalidade de 50\% para JB (20 horas-aula), 75\% para JBD (30 horas-aula) e 100\% para JEIF, J40 e J30 (40 horas-aula), do valor máximo do Prêmio. Em 2011, esse valor foi de R\$2.400,00 para JEIF, sendo o mesmo do ano anterior.

Em 2011, o governo municipal criou o Índice de Qualidade da Educação (Indique), que consiste num novo indicador calculado com base nos resultados da Prova São Paulo, na melhoria dos resultados da escola (esforço) e no perfil socioeconômico dos alunos. O indicador é calculado para cada escola e será utilizado para definir o valor do bônus pago aos profissionais da educação a partir de 2013, quando o PDE deixará de existir.

\footnotetext{
${ }^{\circ}$ A Lei no $14.588 / 07$ define salário bruto mensal como "a soma de todos os valores a que fazem jus os servidores como parte de seus vencimentos mensais, excluindo-se apenas os pagos a título de auxíliotransporte, auxílio-refeição, 1/3 (um terço) de férias, abono de permanência e vantagens indenizatórias ou eventuais".
}

\section{Considerações finais}

A análise do plano de carreira dos profissionais da educação municipal de São Paulo permite afirmar que, em linhas gerais, os aspectos referentes à forma de ingresso, à composição da jornada de trabalho, à progressão e à composição da remuneração foram contemplados na legislação. 
Entre esses aspectos, destaca-se a existência de uma jornada de trabalho que possui $1 / 3$ de sua totalidade reservada a atividades de formação, de preparação das aulas e de trabalho coletivo. No entanto, o fato de essa composição não se aplicar a todas as jornadas previstas no plano de carreira limita as possibilidades de os professores contarem com o tempo destinado a atividades pedagógicas que são realizadas extraclasse. Essa medida vem se tornando comum em parte das jornadas adotadas, pois, apesar de manter a aparência de atendimento à complexidade da atividade docente, permite a adoção de formas indignas de trabalho no magistério, em especial as que excluem ou reduzem significativamente as indispensáveis horas de trabalho coletivo na escola.

Soma-se a isso a possibilidade de, por meio de acúmulo de cargo ou jornada complementar de trabalho, o professor poder trabalhar até 70 horas semanais, anulando a reivindicação histórica de uma jornada compatível com a especificidade do trabalho docente.

É verdade que essa realidade não é específica do magistério da cidade de São Paulo, estando presente em todo o País. No entanto, o fato de a $\mathrm{CF} / 88$ estabelecer a jornada máxima de 44 horas semanais e oito horas diárias parece não incomodar os dirigentes educacionais que têm adotado, até em textos legais, carga horária de trabalho com limites superiores a oito horas diárias. Veja-se como exemplo o art. 19 da Lei no 14.660/2007, em clara desobediência à $\mathrm{CF} / 88$ : "Em regime de acúmulo de cargos, inclusive em outros entes federativos, o profissional de educação não poderá exceder a carga horária de trabalho semanal de 70 (setenta) horas" (grifos dos autores). Ou seja, encontram-se profissionais do magistério que acumulam um cargo de gestor (40 horas) e um cargo de professor (30 horas-aula), somando praticamente 14 horas de trabalho/dia.

A existência de diferentes jornadas de trabalho contraria o proposto no Parecer CNE/CEB nº 9/2009, que sugere às redes de ensino a adoção de uma única jornada de trabalho, de modo a vincular o professor numa mesma escola. Importa dizer, também, que a legislação municipal não faz referência à dedicação exclusiva, ${ }^{11}$ alternativa viável para desestimular o acúmulo de cargo e vincular os profissionais do magistério num único emprego e numa única escola.

Em relação à dispersão no vencimento, estimada em até 100\%, pode-se dizer que está em consonância com as discussões atuais sobre as carreiras do magistério. Embora essa dispersão possa significar um vencimento inicial mais baixo, considerando-se o montante de recursos aplicados, é atrativa na medida em que o professor tem expectativa de melhores salários no decorrer do tempo de serviço.

Um aspecto positivo constatado em relação ao magistério paulistano é o número surpreendentemente alto de professores efetivos da rede municipal (90\%), situação destoante do resto do País, uma vez que somente cerca de 50\% dos professores das diferentes redes públicas são efetivos.

Em relação à composição da remuneração, pode-se destacar o fato de o piso profissional dos professores da rede municipal de São Paulo ser superior ao piso salarial profissional nacional, correspondendo, em
${ }^{11}$ Em geral, entre o Regime de Dedicação Exclusiva e o Regime de 40 horas há uma diferença no vencimento de mais de $50 \%$. 
2011, a $\mathrm{R} \$ 2.152,27$ por uma jornada de 30 horas (40 horas-aula) para o professor com formação em nível médio, e a $\mathrm{R} \$ 2.600,00$ pela mesma jornada para o professor com licenciatura plena. O piso salarial profissional nacional mínimo, em 2011, foi de $\mathrm{R} \$ 1.187,00$ pela jornada de 40 horas semanais de trabalho para o professor com formação em nível médio. No entanto, dado o fato de se tratar do Estado e da cidade mais ricos do País e com um dos mais altos custos de vida, pode-se afirmar que não se caracteriza um piso salarial que se destaque no País como exemplo de valorização do magistério.

Em consequência, a remuneração do professor da rede municipal acaba sendo mais atrativa por conta da progressão na carreira (promoção e evolução) e dos quinquênios e da sexta parte que são incorporados para efeitos de aposentadoria, não se desconsiderando as diferentes gratificações que lhe são concedidas.

O plano de carreira dos docentes, nos aspectos analisados, contempla, em grande medida, a preocupação com uma progressão funcional atrativa para os ingressantes, com a ponderação necessária de que a avaliação de desempenho ainda não faz parte dos critérios atuais de evolução funcional, ainda que "certificados de valoração profissional" estejam previstos nos arts. 35, 38 e 40 da Lei no 14.660/2007. Dado que a avaliação de desempenho é um item presente em praticamente toda a legislação referente aos planos de carreira do magistério do País, é mister o aprofundamento teórico e prático sobre as relações entre valorização profissional, avaliação de desempenho e melhoria da qualidade do ensino.

Para Morduchowicz (2003), à semelhança do que ocorre na América Latina, no caso de São Paulo, trata-se de uma carreira calcada em concepções tradicionais, na medida em que a progressão está baseada, principalmente, no tempo de serviço e na titulação e não na avaliação de desempenho, considerada mais "moderna" e adequada para mensurar a dedicação e a competência dos professores, conforme tem sido defendido por alguns autores (Abreu; Balzano, 2001).

No entanto, apesar da pouca discussão sobre a repercussão desse novo entendimento sobre as relações profissionais no magistério, legislações que incorporaram a avaliação de desempenho já tinham sido aprovadas em 2010, em 14 Estados brasileiros. Trata-se de leis que introduziram a avaliação de desempenho profissional do docente vinculada ao desempenho dos alunos (em especial, contabilizando o número de acertos nas provas nacionais e/ou estaduais e municipais) como condição para novos ganhos salariais, estes sempre como "gratificações" que não se incorporam ao vencimento-base.

O Índice de Desenvolvimento da Educação Básica (Ideb), criado em 2007 pelo MEC, tem sido um dos principais motivadores para que Estados e municípios adotem essa fórmula, acreditando-se constituir "motivação" para os professores, com vistas ao alcance de metas estabelecidas, parte delas improváveis, quando analisadas as circunstâncias e as condições materiais do trabalho escolar e docente. 
Esse tipo de avaliação tem contaminado as propostas atuais de planos de carreira e de estatutos do magistério, trazendo o critério da "competição" entre pares e da meritocracia como importante fator de motivação para uma atuação docente mais criativa, dinâmica e atualizada. Na nova fórmula, substitui-se a isonomia salarial, que, historicamente, fundamentou o trabalho coletivo como condição de sucesso de uma escola e de uma equipe de professores e especialistas, por uma competição entre pares, na qual quem se destaca dos outros deve ser premiado para continuar "motivado" a se dedicar. Em compensação, aos "acomodados", o mínimo da remuneração deve ser mantido, na tentativa de "convencêlos" de que, se quiserem ganhar mais, terão de se dedicar mais e sempre.

Mesmo que os (poucos) estudos realizados, de forma independente, mostrem que esta nova fórmula: $>$ salário $=>$ produtividade $=>$ qualidade de ensino não tem suporte na realidade escolar, a mídia e os empresários, que vêm atuando cada vez mais no ambiente educacional, insistem em estabelecer, como critério para sua "cooperação", essa equação, para garantir, à semelhança de suas empresas, o sucesso do produto "educação pública cidadã" no input professor competente + salários um pouco mais altos $=$ melhores resultados nas provas nacionais, estaduais e municipais.

A legislação brasileira referente aos planos de carreira dos profissionais da educação, desde a LDB/96, tem contemplado a avaliação de desempenho como um dos requisitos para a progressão na carreira. Entretanto, a forma como essa avaliação consta dos planos e o peso que ela representa na carreira parecem estar diretamente vinculados às concepções dos gestores municipais e estaduais, às negociações com os sindicatos e à mobilização dos profissionais do magistério.

Em São Paulo, na rede municipal de ensino, o PDE e, a partir de 2013, o Índice de Qualidade da Educação (Indique) são bons exemplos dessa política de premiação, pois introduzem essa remuneração de maneira pontual, não a incorporando à carreira. Uma observação importante é que, embora a carreira municipal de São Paulo não esteja calcada na avaliação de desempenho, o plano já contém um embrião do que poderá vir a ser um sistema de avaliação vinculado à remuneração, a depender de como será regulamentada a "certificação de valoração profissional" e o Indique.

A não regulamentação possivelmente permanece pela pressão dos sindicatos, que historicamente consideram esse critério um dos mais injustos para com os professores por não abranger suas condições de trabalho e ensino. O momento é de atenção e resistência, pois, se os sindicatos municipais não tiverem uma atuação política competente para "brecar" esse processo, em breve poder-se-á discutir em São Paulo se os "certificados de valoração profissional" não terão se transformado no principal critério para a evolução funcional do magistério paulistano.

Diante disso, ficam os seguintes questionamentos: poderá um processo de monitoramento das unidades de ensino garantir, ao mesmo tempo, a melhoria da qualidade de ensino, a valorização dos profissionais da educação e a eficiência institucional, como pretende a legislação 
municipal? Ou trata-se de artifícios para que a competitividade, e não mais o trabalho coletivo, dirija as ações e os projetos educacionais nas escolas públicas? Interessam, aliás, os projetos pedagógicos diferenciados em cada uma das escolas públicas ou a uniformidade e sua implementação são que definirão o critério de sua excelência?

\section{Referências bibliográficas}

ABREU, Mariza Vasques de; BALZANO, Sônia. Progressão na carreira do magistério e avaliação de desempenho. In: RODRIGUES, Maristela M.; GIÁGIO, Mônica (Org.). Guia de consulta para o Programa de Apoio aos Secretários Municipais de Educação: PRASEM III. Brasília: FUNDESCOLA/MEC, 2001.

BRASIL. Constituição da República Federativa do Brasil: promulgada em 5 de outubro de 1988. Brasília, 5 out. 1988. Disponível em: < http:// www.planalto.gov.br/ccivil_03/constituicao/constituicao.htm>.

BRASIL. Emenda Constitucional no 14, de 12 de setembro de 1996. Modifica os arts. 34, 208, 211 e 212 da Constituição Federal e dá nova redação ao art. 60 do Ato das Disposições constitucionais Transitórias. Brasília, 1996. Disponível em: < http://www.planalto.gov.br/ccivil_03/ constituicao/Emendas/Emc/emc14.htm>.

BRASIL. Lei no 9.394, de 20 de dezembro de 1996. Estabelece as Diretrizes e Bases da Educação Nacional. Brasília, 1996. Disponível em: <http://www.planalto.gov.br/ccivil_03/leis/19394.htm>

BRASIL. Lei no 9.424, de 24 de dezembro de 1996. Dispõe sobre o Fundo de Manutenção e Desenvolvimento do Ensino Fundamental e Valorização do Magistério, na forma prevista no art. 60, § $7^{\circ}$ do Ato das Disposições Constitucionais Transitórias e dá outras providências. Brasília, 1996. Disponível em: <http://www.planalto.gov.br/ccivil_03/leis/19424.htm>

BRASIL. Emenda Constitucional no 19, de 4 de junho de 1998. Modifica o regime e dispõe sobre princípios e normas da Administração Pública, servidores e agentes políticos, controle de despesas e finanças públicas e custeio de atividades a cargo do Distrito Federal, e dá outras providências. Brasília, 1998. Disponível em: < http://www.planalto.gov. br/ccivil_03/constituicao/Emendas/Emc/emc19.htm>

BRASIL. Lei no 11.738, de 16 de julho de 2008. Regulamenta a alínea "e" do inciso III do caput do art. 60 do Ato das Disposições Constitucionais Transitórias, para instituir o piso salarial profissional 
nacional para os profissionais do magistério público da educação básica. Brasília, 2008. Disponível em: < http://www.planalto.gov.br/ ccivil_03/_ato2007-2010/2008/lei/l11738.htm>.

BRASIL. Ministério da Educação (MEC). Conselho Nacional de Educação (CNE). Parecer CNE/CEB no 9/2009, aprovado em 2 de abril de 2009. Revisão da Resolução CNE/CEB n 3/97, que fixa Diretrizes para os novos Planos de Carreira e de Remuneração para o Magistério dos Estados, do Distrito Federal e dos Municípios. Brasília, 2009a. Disponível em: <http://portal.mec.gov.br/dmdocuments/pceb009_09.pdf>.

BRASIL. Ministério da Educação (MEC). Conselho Nacional de Educação (CNE). Resolução do CNE/CEB n 2 de 28 de maio de 2009. Fixa as Diretrizes Nacionais para os Planos de Carreira e Remuneração dos Profissionais do Magistério da Educação Básica Pública, em conformidade com o artigo $6^{\circ}$ da Lei no 11.738 , de 16 de julho de 2008, e com base nos artigos 206 e 211 da Constituição Federal, nos artigos 8º, § $1^{\circ}$, e 67 da Lei $n^{\circ}$ 9.394, de 20 de dezembro de 1996, e no artigo 40 da Lei ${ }^{\circ}$ 11.494, de 20 de junho de 2007. Brasília, 2009b. Disponível em: < http:// portal.mec.gov.br/dmdocuments/resolucao_cne_ceb002_2009.pdf $>$.

DUTRA JÚNIOR, Adhemar F. et al. Plano de carreira e remuneração do magistério público: LDB, FUNDEF, Diretrizes nacionais e nova concepção de carreira. Brasília: FUNDESCOLA/MEC, 2000.

GATTI, Bernadete Angelina; BARRETO, Elba Siqueira de Sá.

Professores do Brasil: impasses e desafios. Brasília: UNESCO, 2009.

MONLEVADE, João Antonio Cabral de. Valorização salarial dos professores: o papel do Piso Salarial Profissional Nacional como instrumento de valorização dos professores da educação básica pública. 2000. Tese (Doutorado em Educação) - Faculdade de Educação, Universidade Estadual de Campinas, Campinas, 2000.

MORDUCHOWICZ, Alejandro. Carreiras, incentivos e estruturas salariais docentes. Rio de Janeiro: PREAL Brasil, 2003.

SÃO PAULO. Prefeitura Municipal. Lei no 8.989, de 29 de outubro de 1979. Dispõe sobre o Estatuto dos Funcionários Públicos do Município de São Paulo e dá providências correlatas. São Paulo, 1979. Disponível em: <http://www.prefeitura.sp.gov.br/cidade/secretarias/upload/ chamadas/Servidores\%20-\%20Estatuto_1265987442.pdf>

SÃO PAULO. Prefeitura Municipal. Lei Orgânica do Município de São Paulo (com suas alterações), de 4 de abril de 1990. Disponível em: <http://www.prefeitura.sp.gov.br/cidade/secretarias/upload/educacao/ cme/LOM.pdf $>$. 
SÃO PAULO. Prefeitura Municipal. Lei no 11.035, de 11 de julho de 1991. Institui a Gratificação de Difícil Acesso, prevista no artigo 95 da Lei Orgânica do Município de São Paulo, e dá outras providências. São Paulo, 1991. Disponível em: <http://webcache.googleusercontent. com/search?q=cache:SDkCPZa_WuEJ:www.prefeitura.sp.gov.br/ cidade/secretarias/upload/Leis\%2520Municipais\%25209_1256741470. $\mathrm{doc}+\& \mathrm{~cd}=1 \& \mathrm{hl}=\mathrm{pt}-\mathrm{BR} \& \mathrm{ct}=\mathrm{clnk} \& \mathrm{gl}=\mathrm{br}>$.

SÃO PAULO. Prefeitura Municipal. Lei no 11.229, de 26 de junho de 1992. Dispõe sobre o estatuto do magistério Público Municipal, e dá outras providências. São Paulo, 1992. Disponível em: < http:// portalsme.prefeitura.sp.gov.br/Documentos/BibliPed/TextosLegais/ LegislacaoEducacional/Lei_11229_EstatutoMagisterioPublico.pdf > .

SÃO PAULO. Prefeitura Municipal. Lei no 11.434, de 12 de novembro de 1993. Dispõe sobre a organização dos Quadros dos Profissionais de Educação, da Prefeitura do Município de São Paulo, e dá outras providências. São Paulo, 1993. Disponível em: < http:// portalsme.prefeitura.sp.gov.br/Documentos/BibliPed/TextosLegais/ LegislacaoEducacional/Lei_11434_12_11_93_OrganizacaoQuadros.pdf > .

SÃO PAULO. Prefeitura Municipal. Lei no 12.858, de 18 de junho de 1999. Institui o Auxílio-Refeição, nas condições que específica, e dá outras providências. São Paulo, 1999. Disponível em: < http:// portalsme.prefeitura.sp.gov.br/Projetos/sitemerenda/Anonimo/ legislacao/leis/lei_12858.aspx>.

SÃO PAULO. Prefeitura Municipal. Lei no 14.244, de 29 de novembro de 2006. Institui a Gratificação de Regência, a Gratificação de Atividade Educativa, a Gratificação de Apoio Educacional, a Gratificação de Atribuição Educacional, a Gratificação Especial para Especialistas, a Gratificação de Apoio à Educação, a Gratificação por Desenvolvimento Sócio-Educativo e o Abono Complementar, a serem concedidos aos servidores que especifica. São Paulo, 2006. Disponível em: < http:// www.prefeitura.sp.gov.br/cidade/secretarias/upload/chamadas/ 114244_1311715323.pdf>.

SÃO PAULO. Prefeitura Municipal. Lei $\mathrm{n}^{\circ}$ 14.588, de 12 de novembro de 2007. Altera a redação dos art. $1^{\circ}$ ao $6^{\circ}$ da Lei Municipal $n^{\circ}$ 13.598/03 e institui o Vale-Alimentação, benefício a ser concedido aos servidores municipais que especifica. São Paulo, 2007. Disponível em: <http://www.prefeitura.sp.gov.br/cidade/secretarias/upload/chamadas/ 114588_1311766307.pdf>.

SÃO PAULO. Prefeitura Municipal. Lei no 14.660, de 26 de dezembro de 2007. Dispõe sobre alterações das Leis $n^{\circ} 11.229$, de 26 de junho de $1992, n^{\circ} 11.434$, de 12 de novembro de 1993 e legislação subsequente, 
reorganiza o Quadro dos Profissionais de Educação, com as respectivas carreiras, criado pela Lei no 11.434, de 1993, e consolida o Estatuto dos Profissionais da Educação Municipal. São Paulo, 2007. Disponível em: $<$ http://portalsme.prefeitura.sp.gov.br/Projetos/BibliPed/Documentos/ Legisla\%C3\%A7\%C3\%A3o/LeiMunicipal14660.pdf> .

SÃO PAULO. Prefeitura Municipal. Lei no 14.709, de 3 de abril de 2008. Dispõe sobre o reajustamento das Escalas de Padrões de Vencimentos dos Quadros dos Profissionais de Educação, a absorção das gratificações instituídas pela Lei $n^{\circ} 14.244$, de 29 de novembro de 2006, na forma que especifica e introduz alterações na Lei $n^{\circ} 14.660$, de 26 de dezembro de 2007. São Paulo, 2008. Disponível em: < http:// www.portalsme.prefeitura.sp.gov.br/Projetos/BibliPed/Documentos/ Legisla\%C3\%A7\%C3\%A3o/LeiMunicipal14709.pdf>.

SÃO PAULO. Prefeitura Municipal. Lei no 14.938, de 30 de junho de 2009. Institui o Prêmio de Desempenho Educacional e revoga as leis e os dispositivos legais que especifica. São Paulo, 2009. Disponível em: <http://www.prefeitura.sp.gov.br/cidade/secretarias/upload/chamadas/ 114938_1311717474.pdf>.

SÃO PAULO. Prefeitura Municipal. Lei no 15.215, de 25 de junho de 2010. Dispõe sobre o reajustamento das Escalas de Padrões de Vencimentos do Quadro dos Profissionais da Educação, mantém a concessão do Abono Complementar que especifica e introduz alterações na Lei no 14.244, de 29 de novembro de 2006; reconfigura a carreira de Agente Escolar, do Quadro de Apoio à Educação, do Quadro dos Profissionais da Educação, prevista na Lei n 14.660 , de 26 de dezembro de 2007, e legislação subsequente. São Paulo, 2010. Disponível em: <http://www.prefeitura.sp.gov.br/cidade/secretarias/ upload/chamadas/115215_1311719873.pdf>.

SÃO PAULO. Protocolo de negociação de 2010 - Educação. Diário Oficial do Município de São Paulo, São Paulo, 3 jun. 2010. p. 63.

SÃO PAULO. Anexo Único a que se refere o artigo $1^{\circ}$ do Decreto $\mathrm{n}^{\circ}$ 52.399/2011. Diário Oficial do Município de São Paulo, São Paulo, 8 jun. 2011. p. 3-4. Disponível em: < http://www.docidadesp.imprensaoficial. com.br/NavegaEdicao.aspx?ClipID=9QD9IJES3JHTVeDUDEIE1LSOAK U\&PalavraChave $=52.399>$.

SÃO PAULO. Prefeitura Municipal. Portaria no 1.566/2008. Dispõe sobre Projetos Especiais de Ação - PEAs e dá outras providências. Disponível em: <http://www3.prefeitura.sp.gov.br/cadlem/secretarias/negocios juridicos/cadlem/integra.asp?alt=19032008P\%20015662008SME $>$. 
SÃO PAULO. Prefeitura Municipal. Lei no 15.490, de 29 de novembro de 2011. Dispõe sobre o reajustamento do Abono Complementar instituído pelo art. 11 da Lei no 14.244, de 29 de novembro de 2006. Diário Oficial da Cidade de São Paulo, São Paulo, 30 nov. 2011.

SÃO PAULO. Sindicato dos Profissionais em Educação no Ensino Municipal de São Paulo. Jornal do Sindicato, n. 172, 2010.

Lisete Regina Gomes Arelaro, doutora em Educação pela Universidade de São Paulo (USP), é professora titular da Faculdade de Educação da USP, São Paulo, Brasil.

liselaro@usp.br

Márcia Aparecida Jacomini, doutora em Educação pela Universidade de São Paulo (USP), é professora do Departamento de Educação da Escola de Filosofia, Letras e Ciências Humanas da Universidade Federal de São Paulo (Unifesp), São Paulo, Brasil.

marciajacomini@uol.com.br

Nilson Alves de Souza, mestre em Educação pela Universidade de São Paulo (USP), é professor da Rede Municipal de Ensino de São Paulo, São Paulo, Brasil.

pedagogia31@yahoo.com.br

Kátia Aparecida Santos, mestre em Educação pela Faculdade de Educação da Universidade de São Paulo (USP), é professora da Rede Municipal de Ensino de São Paulo,São Paulo, Brasil.

katcabre@yahoo.com.br

Recebido em 13 de julho de 2013.

Aprovado em 17 de dezembro de 2013. 